\title{
PERANCANGAN SISTEM INFORMASI PENYEWAAN MESIN FOTOCOPY PADA PT. TRIMULIA NUGRAHA MENGGUNAKAN JAVA NETBEANS
}

\author{
Achmad Maulana Septiyan', Irawan Setiadi ${ }^{2}$, Nurul Frijuniarsi $^{3}$ \\ 1,2,3 Teknik Informatika, Fakultas Teknik dan Ilmu Komputer Universitas Indraprasta PGRI Jakarta \\ Jl. Raya Tengah No. 80, Kel. Gedong, Kec. Pasar Rebo, Jakarta Timur \\ ${ }^{1}$ achmadmaulanaseptiyan@gmail.com, ${ }^{2}$ irawan.setiadi91@gmail.com, ${ }^{3}$ frijuniarsinurul@gmail.com
}

\begin{abstract}
ABSTRAK
PT Trimulia Nugraha merupakan perusahaan swasta yang bergerak di bidang jasa penyewaan dan jual beli mesin fotocopy. Dalam penyimpanan dan mengelola data yang digunakan masih menggunakan Microsoft Office Excell ini membuat data belum terdokumentasi dengan baik dan menyulitkan pada saat mencari data yang dibutuhkan. Untuk menyempurnakan hasil penelitian ini, penulis menggunakan metode waterfall yaitu communication (komunikasi), planing (perencanaan), modeling (pemodelan), construction (kontruksi), deployment (implementasi) \& maintance (pemeliharaan). Tujuan dari penelitian ini untuk membangun sebuah sistem informasi yang mengatur data penyewaan mesin fotocopy yang efisien, maka perlu adanya solusi untuk menjawab kebutuhan akan informasi yang lebih cepat, lebih efisien serta akurat mengenai data penyewaan mesin fotocopy yaitu dengan membangun sebuah sistem informasi. Sistem informasi yang dihasilkan dengan dibuatnya perancangan sistem informasi penyewaan mesin fotocopy pada PT. Trimulia Nugraha yang telah terkomputerisasi mempermudah pengolahan data menjadi lebih efektif dan efisien, dengan adanya aplikasi penyewaan mesin fotocopy ini admin lebih mudah mendata mesin fotocopy dan melakukan pencarian mesin fotocopy dengan lebih cepat, serta mempermudah dalam pembuatan surat sewa mesin dan surat pengembalian mesin fotocopy.
\end{abstract}

Kata Kunci: Sistem Informasi, Penyewaan Mesin Fotocopy, Java, Netbeans

\section{ABSTRACT}

PT Trimulia Nugraha is a private company engaged in the rental and buying, and selling of photocopiers. In storing and managing data, they still use Microsoft Office Excel; this makes the data not well documented and makes it challenging to find the data needed. To improve the results of this study, the author uses the waterfall method, namely communication, planning, modelling, construction, deployment \& maintenance. The purpose of this research is to build an information system that manages efficient photocopier rental data, so there is a need for a solution to answer the need for faster, more efficient and accurate information regarding photocopy machine rental data, namely by building an information system-the information system generated by the design of a photocopy machine rental information system at PT. Trulia Nugraha, which has computerized, makes it easier for data processing to be more effective and efficient. With this photocopier rental application, the admin makes it easier to register photocopiers and search for photocopiers more quickly and make it easier to make machine rental letters and photocopier return letters.

Key Word: Information Systems, Photocopier Rental, Java, Neatbeans

\section{PENDAHULUAN}

Perkembangan teknologi informasi yang sangat cepat saat ini membuat banyak perusahaan melakukan upaya perbaikan untuk membuat perusahaan menjadi lebih maju dan berkembang. Adanya suatu sistem informasi pada suatu perusahaan dapat sangat membantu dalam membangun kualiatas maupun kinerja pada perusahaan. Karena sistem informasi dapat digunakan untuk menampilkan informasi dengan cepat dan dapat menghindarkan dari kesalahan-kesalahan yang disebabkan oleh user atau pegawai, staff dan manajer. Selain lebih cepat dari aspek penyajian data yang lebih mudah, sistem informasi juga dapat menghemat ruang yang biasa digunakan sebagai tempat pengalokasian dokumen atau berkas dari system yang masih manual. Hal ini terjadi dikarenakan sistem informasi mengubah kumpulan data menjadi database yang disimpan dalam komputer dan tidak memenuhi ruangan.

PT Trimulia Nugraha merupakan perusahaan swasta yang bergerak di bidang jasa penyewaan dan jual beli mesin fotocopy. Terdapat 4 (empat) Divisi yang ada yaitu Admin, Kepala Teknisi, Bagian Keuangan, dan 
Kepala Gudang. Pada Kepala Teknisi terdapat divisi dibawahnya yaitu teknisi yang bertugas menginstal mesin fotocopy yang telah di sewa. Dalam penyimpanan dan pengolahan data masih menggunakan Microsoft Office Excell sehingga belum terdokumentasi dengan baik dan menyulitkan pada saat mencari data yang dibutuhkan.

Berdasarkan permasalahan di atas perlu adanya sebuah sistem informasi untuk mengatur data penyewaan mesin fotocopy yang efisien. Dan berdasarkan permasalahan tersebut juga maka perlu adanya solusi untuk menjawab kebutuhan akan informasi yang lebih cepat, lebih efisien serta akurat mengenai data penyewaan mesin fotocopy yaitu dengan membangun sebuah sistem informasi.

Pengertian sistem menurut Azhar Susanto (2013:22) "Sistem adalah kumpulan/group dari sub sistem/bagian/ komponen apapun baik phisik atau pun non phisik yang saling berhubungan satu sama lain dan bekerja sama secara harmonis untuk mencapai satu tujuan tertentu."

Sistem informasi menurut Yaqub (2012:17), definisi sistem informasi adalah Suatu sistem di dalam suatu organisasi yang mempertemukan hubungan pengelolaan data transaksi harian, mendukung operasi, bersifat manajerial dan kegiatan strategi dari suatu organisasi serta menyediakan pihak luar tertentu dengan laporan-laporan yang diperlukan.

Dari pengertian di atas dapat dikatakan bahwa sistem informasi adalah sekumpulan komponen pembentuk sistem mempunyai keterkaitan antara satu komponen dengan komponen lainnya yang bertujuan menghasilkan suatu informasi dalam suatu bidang tertentu.

Tujuan dibuat penelitian ini adalah untuk informasi penyewaan mesin fotocopy yang masuk dan keluar lebih terdata dengan jelas, tidak ada lagi kesulitan dalam mencari ketersediaan mesin fotocopy yang tersedia pada gudang serta efisiensi waktu bagi pegawai dan mengimplementasikan penyewaan mesin fotocopy pegawai melakukan penginputan form pada komputer sehingga lebih terdata dan akurat.
Manfaat dari perancangan sistem Penyewaan Mesin Fotocopy yang dihasilkan agar dapat digunakan dan bermanfaat serta dijadikan sebagai bahan pertimbangan dalam upaya perbaikan masalah yang terkait dengan pendataan mesin, penyewaan dan pengembalian mesin pada PT Trimulia Nugraha dan dapat bermanfaat bagi para pegawai untuk meningkatkan kinerja serta untuk memudahkan dalam proses penyewaaan dan pengembalian mesin fotocopy.

\section{METODE PENELITIAN}

Dalam melakukan sebuah penelitian senantiasa diperlukan suatu metode penelitian yang sesuai dengan pokok permasalahan yang akan diteliti. Metode penelitian yang dilakukan adalah Metode Grounded Research yaitu suatu metode penelitian berdasarkan pada fakta dan menggunakan analisis perbandingan dengan tujuan mengadakan generalisasi empiris, menetapkan konsep, membuktikan teori, mengembangkan teori, pengumpulan, dan analisis data dalam waktu yang bersamaan. Dalam riset ini, data merupakan sumber teori atau teori berdasarkan data. Dalam pengumpulan data untuk merancang sistem yang layak digunakan, maka penulis menggunakan 1 (satu) metode yaitu :

\section{Observasi / Pengamatan}

Observasi atau pengamatan merupakan salah satu teknik untuk pengumpulan data untuk penelitian, dilakukan secara langsung ke lapakan pada PT Trimulia Nugraha melihat mengenai proses pendataan mesin fotocopy, proses penyewaan mesin fotocopy, serta proses pengembalian mesin fotocopy. Pengamatan ini dilakukan pada bulan Maret sampai dengan bulan Juni 2021 demi mengetahui data apa saja yang masih belum lengkap yang tidak kita dapat dari hasil wawancara.

\section{Wawancara}

Wawancara merupakan suatu percakapan diantara dua orang dan tercatat atau percakapan yang dilakukan secara tatap muka dimana seseorang memperoleh informasi dari orang lain. Penulis melakukan wawancara di PT Trimulia Nugraha dan bertemu dengan Ibu Chairunnisa sebagai admin pada tanggal 2 Maret 2021, beliau menyatakan bahwa permasalahan dalam sistem informasi penyewaan mesin fotocopy saat ini masih 
belum terkelola dengan efektif, penggunaan sistem yang seadanya membuat beberapa kali terjadi kesalahan. Cara yang masih dilakukan ini perlu dirubah menjadi terkomputerisasi dan dibuatkan sistem aplikasi untuk mengolah data-data yang berhubungan dengan data penyewaan mesin fotocopy agar lebih efektif.

\section{Langkah-langkah pengembangan sistem}

Untuk menyempurnakan hasil penelitian ini, penulis menggunakan metode waterfall. Menurut Pressman (2015:42), model waterfall adalah model klasik yang bersifat sistematis, berurutan dalam membangun software.

Tahapan dari metode waterfall adalah sebagai berikut:

Communication

Pada tahap penhembangan sebuah sistem sangat diperlukan komunikasi yang bertujuan mengetahui perangkat lunak yang diharapkan oleh pengguna dan batasan perangkat lunak tersebut.

\section{Planning}

Di tahap ke-dua adalah perencanaan yang menjelaskan mengenai tugas teknis yang akan dilakukan, resiko yang mungkin terjadi, sumber daya yang diperlukan dalam membuat sistem, produk kerja yang akan dihasilkan, penjadwalan kerja yang akan dilaksanakan, dan tracking proses pengerjaan sistem.

\section{Modeling}

Ditahap ke-tiga adalah tahap permodelan arsitektur sistem dan perancangan yang akan berfokus pada perancangan struktur data, arsitektur software, interface, dan algoritma program.

\section{Construction}

Tahapan ke-empat ini merupakan proses penerjemahan bentuk desain menjadi sebuah kode yang dapat dibaca oleh mesin. Selanjutnya melakukan pengujian terhadap sistem dan juga kode yang telah dibuat.

\section{Deployment}

Tahapan ke-lima adalah tahapan untuk implementasi software ke customer, pemeliharaan software secara berkala, perbaikan software, evaluasi software, dan pengembangan software berdasarkan saran yang diberikan agar sistem dapat tetap berjalan dan berkembang sesuai dengan fungsinya.

\section{HASIL DAN PEMBAHASAN \\ Analisis Penelitian}

Dari hasil penelitian yang penulis lakukan maka penulis dapat menganalisa permasalahan yang ada pada sistem penyewaan mesin fotocopy di PT Trimulia Nugraha yaitu :

1. Kesulitan dalam mencari data mesin fotocopy yang tersedia.

2. Belum adanya laporan perbulan mengenai data mesin fotocopy, penyewaan dan pengembalian mesin fotocopy.

3. Belum tersedianya sistem informasi penyewaan mesin yang bisa di akses oleh pegawai mengenai ketersediaan mesin fotocopy.

\section{Alternatif Penyelesaian Masalah}

Berdasarkan masalah - masalah yang dihadapi PT Trimulia Nugraha, maka penulis memberikan alternatif penyelesaian masalahnya, yaitu:

1. Perancangan aplikasi mencakup:

a. Pengelolaan data karyawan

b. Pengelolaan data pelanggan

c. Pengelolaan data mesin fotocopy

d. Pengelolaan sewa mesin fotocopy

e. Pengelolaan pengembalian mesin fotocopy

2. Pengolahan data akan menghasilkan informasi berupa laporan data karyawan, laporan data pelanggan, laporan data mesin fotocopy, laporan sewa mesin dan laporan pengembalian mesin fotocopy.

3. Sistem aplikasi ini bersifat client server dan hanya digunakan untuk pengelolaan data pada PT Trimulia Nugraha yang dikembangkan berdasarkan kebutuhan user menurut fungsinya.

\section{Diagram Alir Data (DAD)}

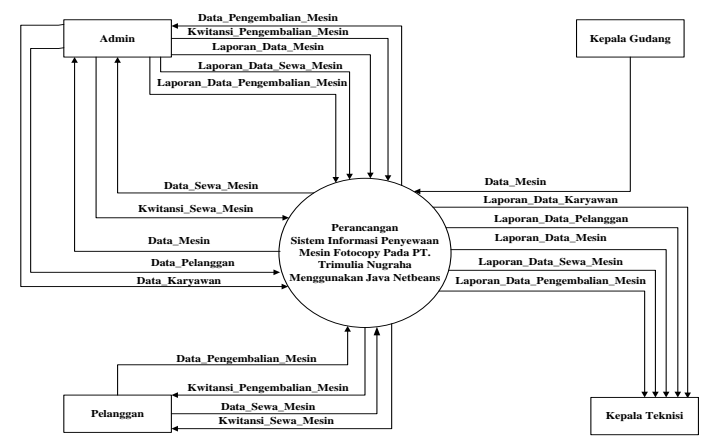

Gambar 1. Diagram Konteks

8o | Perancangan Sistem Informasi Penyewaan Mesin Fotocopy pada PT. Trimulia Nugraha Menggunakan Java Netbeans 


\section{Normalisasi}

Menurut Ichwan "Normalisasi data merupakan suatu teknik yang dapat mengarahkan suatu perancangan dapat penggunaan ruang simpan, cepat melakukan perubahan.(Ichwan, 2011). Dalam teori normalisasi data ada lima tahapan untuk mencapai suatu basis data yang efisien.

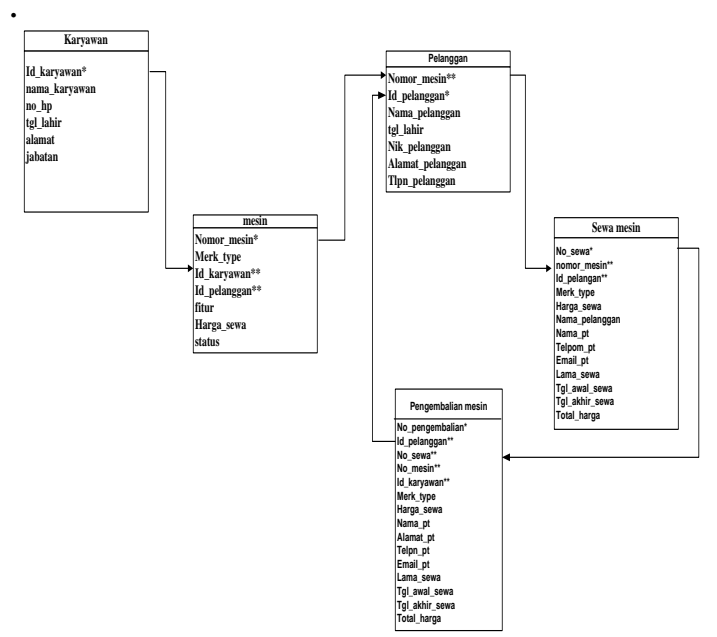

Gambar 2. Normalisasi

\section{ERD (Entity Relationship Diagram)}

Entity Relation Diagram (ERD) merupakan suatu bentuk diagram yang menjelaskan objekobjek data yang mempunyai keterkaitan antar relasi. Entity Relation Diagram (ERD) dari perancangan sistem informasi penyewaan mesin fotocopy pada PT Trimulia Nugraha adalah sebagai berikut :

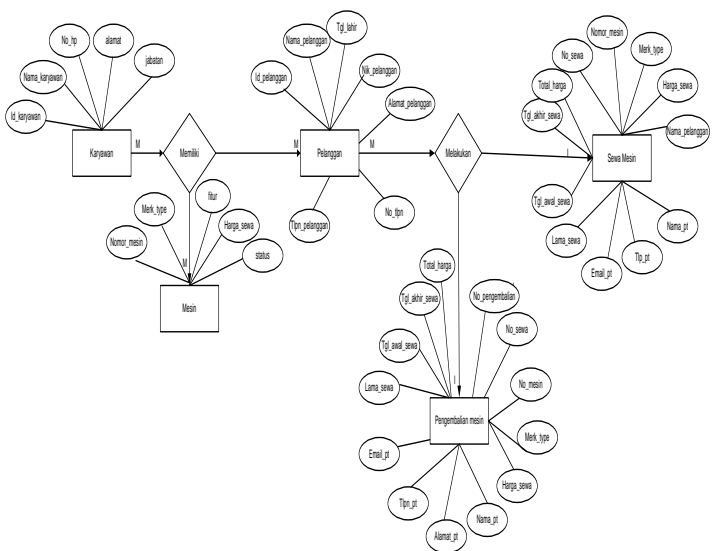

Gambar 3. Entitas Relationship Diagram (ERD)

\section{Tampilan Layar Sistem Informasi Penyewaan Mesin Fotocopy Pada PT Trimulia Nugraha}

Form login ini muncul di awal pengoperasian program perancangan sistem infromasi penyewaan mesin fotocopy untuk diisi oleh admin sebagai user. Masukan username dan password yang sesuai dengan hak akses supaya biasa mengoperasikan sistem informasi penyewaan mesin fotocopy. Jika username dan password sesuai, maka akan masuk kepada tampilan Menu Utama.

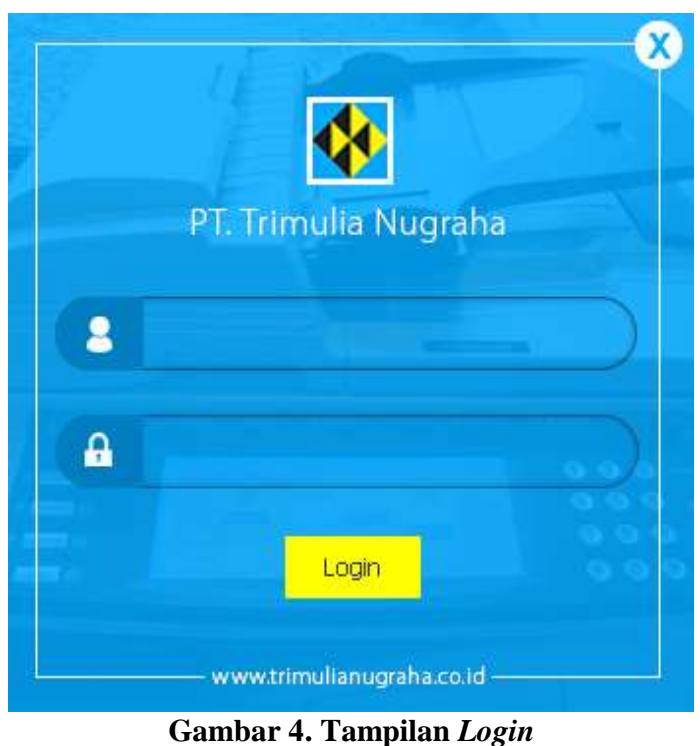

Tampilan menu utama aplikasi system informasi penyewaan mesin fotocopy. Setelah user berhasil melewati menu login. Pada menu utama ini terdapat beberapa menu yang akan menampilkan form dan informasi diantaranya adalah data karyawan, data pelanggan, data mesin, data sewa mesin, data pengembalian mesin dan laporan.

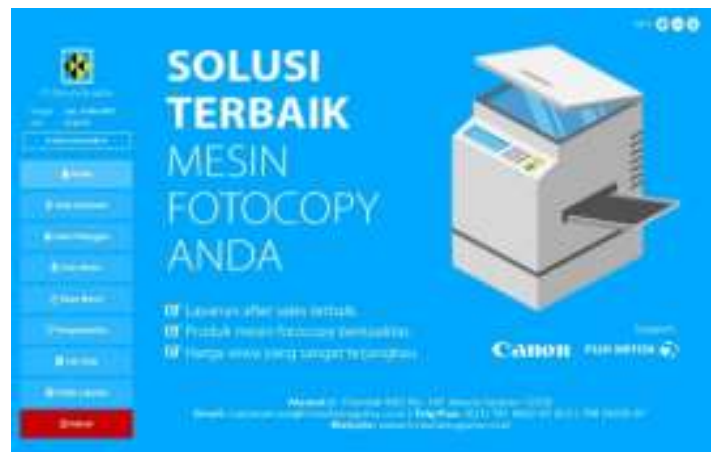

Gambar 5. Tampilan Menu Utama

Tampilan data sewa mesin ini terdapat tombol simpan untuk menyimpan data sewa mesin fotocopy, tombol edit apabila ingin merubah data sewa mesin fotocopy yang sudah tersimpan di dalam tabel, tombol hapus apabila ingin menghapus data sewa mesin fotocopy yang sudah tersimpan di dalam tabel, tombol hapus apabila ingin menghapus data sewa mesin fotocopy yang sudah tersimpan, tombol reset untuk mereset text yang sudah kita ketik 
sebelumnya dan tombol print untuk mencetak form sewa mesin fotocopy.

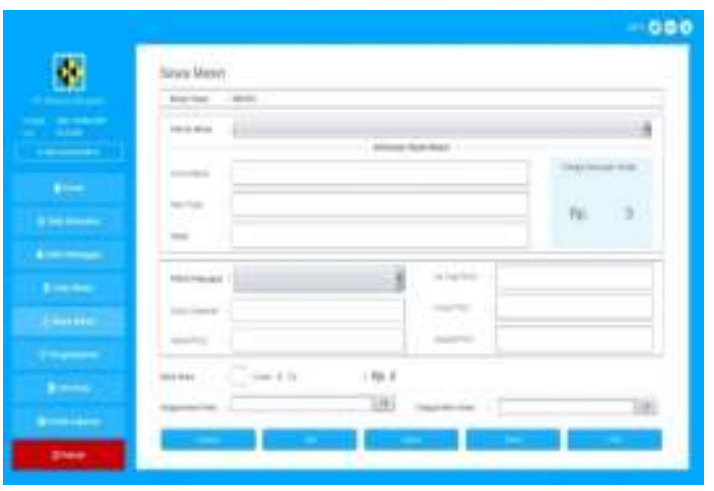

Gambar 6. Tampilan Sewa Mesin Fotocopy

Tampilan laporan data sewa mesin fotocopy ini berisi data-data yang ada pada tabel sewa mesin fotocopy. Laporan ini muncul ketika user mengklik tombol cetak laporan data sewa mesin pada tampilan menu utama.

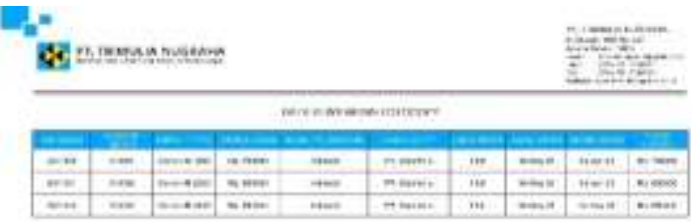

Gambar 7. Tampilan Laporan Data Sewa Mesin Fotocopy pada PT Trimulia Nugraha

\section{SIMPULAN DAN SARAN}

Dengan perancangan aplikasi ini proses pengolahan data mesin, data pelanggan, data sewa mesin, data pengembalian mesin, surat instalasi mesin dan surat pengembalian mesin yang selama ini dilakukan secara manual dapat dipermudah dengan rancangan sistem yang terkomputerisasi serta efisien dalam proses pencarian data dan pembuatan laporan.

Dengan adanya sistem ini input dilakukan secara terkomputerisasi sehingga data lebih akurat sehingga dapat mempermudah dan mempercepat pencarian data mesin fotocopy dan dalam laporan karena data yang di input kedalam sistem secara langsung akan diproses menjadi suatu informasi laporan.

Dari kesimpulan yang telah diambil, maka penulis ingin memberikan saran kepada PT Trimulia Nugraha yang mungkin nanti akan menjadi pertimbangan yaitu dengan penambahan sistem diskon bagi para pelanggan yang sudah menyewa mesin lebih dari satu tahun, serta menambahkan sistem untuk perawatan atau maintance mesin secara rutin.

\section{DAFTAR PUSTAKA}

Al-Bahra. (2013). Analisis dan Desain Sistem Informasi. Graha Ilmu.

Buana. (2014s). Pemrograman Database $M y S Q L$. MediaKom.

Husein Umar. (2013). Metode Penelitian Untuk Skripsi dan Tesis. Rajawali.

Ichwan. (2011). Pemrograman Basis Data: Microsoft visual basic 6.0 dan MySql. Andi Publisher.

Jogiyanto, H. M. (2011). Analisis Perancangan Sistem Informasi. Andi Publisher.

Pressman. (2015). Rekayasa Perangkat Lunak: Pendekatan Praktisi Buku I. Andi Publisher.

Sugiyono. (2013). Metode Penelitian Kualitatif dan $R \& D$. Alfabeta.

Sukamto, \& S. (2013). Analisa dan Desain Sistem Informasi. Andi Offset.

Susanto, A. (2013). Sistem Informasi Akuntansi. Lingga Jaya.

Sutabri. (2014). Pengantar Teknologi Informasi. Andi.

Yaqub. (2012). Pengantar Sistem Informasi. Graha ilmu. 